Article

\title{
Exploration of the Industrial Spatial Linkages in Urban Agglomerations: A Case of Urban Agglomeration in the Middle Reaches of the Yangtze River, China
}

\author{
Yan Yu ${ }^{1, *}$, Qianwen Han ${ }^{1, *}$, Wenwu Tang ${ }^{2}$, Yanbin Yuan ${ }^{1}$ and Yan Tong ${ }^{1}$ \\ 1 Department of Regional Planning and Management, School of Resources and Environmental Engineering, \\ Wuhan University of Technology, Wuhan 430070, China; yybjm@126.com (Y.Yuan); yaner_t@163.com (Y.T.) \\ 2 Center for Applied Geographic Information Science, Department of Geography and Earth Sciences, \\ University of North Carolina at Charlotte, Charlotte, NC 28223, USA; WenwuTang@uncc.edu \\ * Correspondence: yyhrose@whut.edu.cn (Y.Yu); hanqianwen@whut.edu.cn (Q.H.); \\ Tel.: +86-139-9564-7018 (Y.Yu); +86-155-2729-1030 (Q.H.)
}

Received: 28 March 2018; Accepted: 4 May 2018; Published: 8 May 2018

\begin{abstract}
The study of industrial spatial linkages of urban agglomerations is crucial to recognizing spatial structure and optimizing regional division and cooperation. The existing studies often focus on external spatial interaction at the inter-city level, but few have considered complex internal economic linkages at the inter-sector level. In this study, we established an integrated framework by combining the wave effect gradient field with the gravity model. The wave effect gradient field was used to analyze the inter-sector relation, while the gravity model was adopted to explore the spatial interactions of industry at the inter-city level. The Urban Agglomeration in the Middle Reaches of the Yangtze River (UAMRYR) was taken as a case study, which demonstrates the applicability of the proposed framework. The results indicate that there exists an imbalanced development in the network of industrial linkages in the study region. Each subgroup has presented a self-organized spatial linkage network, but the linkages between subgroups are immature. Compared with other sectors, the high-tech and internet industrial sectors contribute most to economic linkages among cities. Thus, policymakers should take actions to strengthen the inter-subgroup spatial linkages and give priority to the high-tech industries, which is necessary for the integrated and sustainable development of UAMRYR.
\end{abstract}

Keywords: input-output theory; gravity model; industrial spatial linkage; urban agglomeration

\section{Introduction}

Regional economic linkages and their spatial structure have become a crucial topic in regional and economic geography [1]. Recently, urban agglomerations become a major spatial form of regional economic development [2]. Urban agglomeration refers to a group of cities in a specific geographic area, often with one megacity as the core and at least three or more major cities. It relies on well-developed infrastructure networks, such as transportation and communication, to form urban communities that are relatively compact and economically connected, and will eventually achieve high integration of urbanization. Industry is the carrier of urbanization and the core of the economic development of urban agglomeration [3]. It plays a crucial role in the formation and development of urban agglomeration. The industrial spatial linkage in urban agglomeration refers to the spatial linkages formed within the region due to the internal technical links among industrial sectors. All industrial sectors should be an integrated system complying with inherent relationships to realize coordinated development 
at the regional level. An imbalanced industrial structure will lead to unreasonable proportions and relationships among different industrial sectors, thus threating the sustainable development of the regional economy. Therefore, it is crucial to study industrial spatial linkages and understand the spatial structure and characteristics of the industrial system, so as to optimize the industrial layout and promote the sustainable development of the urban agglomeration area.

Since the 1920s, industrial spatial linkages, as an important part of the regional economy, have attracted widespread attention from many scholars. As early as 1826, von Thünen's agricultural location theory and Weber's industrial location theory in 1909 have been used to study the layout of agriculture and industries, respectively, from the perspective of industrial spatial linkage. These location theories then became important theoretical foundations for economic geography [4]. In 1950, the French economist Perroux proposed the "Growth-Pole" and "Growth-Center" theory to describe the industry's layout of cities [5]. Subsequently, Friedmann and Pred established the "Spatial Interaction Theory" and "Spatial Diffusion Theory" and conducted research on the spatial structure and organization of economic linkages in urban agglomeration, from the perspective of urban operations management [6,7]. These studies have provided a sufficient theoretical basis for the study of industrial spatial linkages. In the 1940s, Zipf introduced the universal gravity model into city systems, and established a spatial interaction model of urban economy [8]. After that, the gravity model has become the most popular method for studying industrial spatial linkages [9-14]. For example, Tan et al. had quantitatively measured the interaction between cities in the Wuhan Metropolitan Area (WMA) based on the gravity model [10]. With the continuous advancement of related research, there are more quantitative models applied to the study of industrial spatial linkages. Djankov et al. used the gravity model to empirically analyze the changes in trade flows between the nine Russian regions of the former Soviet Union and the three former Soviet republics from 1987 to 1996 [11]. Li et al. compared changes in the industrial structure of China and Japan by combining input-output analysis with social network analysis [15]. Wang et al. studied the spatial linkages of the urban economy for the Pearl River Delta in China from the perspective of industry, based on the urban flow intensity model [16]. Sun et al. examined the economic network structure of urban agglomeration in the middle reaches of the Yangtze River by integrating social network analysis and a modified gravity model [9]. Although these studies have showed insightful findings and made great contributions to the study of regional economy, they often focused on the external spatial interaction of regional economy, with few taking into account the complex internal economic linkages between different industrial sectors at the regional level. In the existing research, the input-output theory is a popular method to study the interactions between different sectors of a region $[9,15,17-19]$. For example, Shi et al. explored the inter-sectoral relations between five provinces of the Inland River Basin in China by adopting input-output analysis, but these studies did not measure the industrial interaction among provinces [18].

Previous literature on industrial spatial linkages has yielded substantial achievements [12,15,20,21]. However, researches engaged in this work have not formed a complete framework. With respect to research themes, the existing studies mainly focused on the spatial configuration of a certain part of an industrial chain, or the spatial relations of a single industry sector (such as trade, transportation, logistics, and information sectors) $[11,13,14,17,22-30]$. These studies can only provide partial references, rather than any more detailed recommendations for regional economic development planning and policy making. In terms of methods, the more commonly used models are the gravity model [9-14], social network analysis $[9,15]$, and the urban flow model [16,21]. Among these models, the gravity model is much more popular to study regional economic linkages due to its simple structure and universal applicability. The economic indicators selected in existing models (e.g., population, GDP, etc.) cannot reflect the mutual influence among different sectors [31]. In fact, the interactions among different sectors in an industry chain are always existing and constantly changing. This will lead to a deviation between analysis results and reality, if the interactions among different sectors were ignored in the study of industrial spatial linkages. Therefore, we attempt to reduce this bias by using the industrial wave effect gradient field [32], which is introduced into regional and industrial economies 
based on the concept of gradient. That is, various industrial sectors in different cities are regarded as points in space. Changes in cost and produce of these points in space are expressed by the gradient, and then a gradient is constructed. The advantage of the industrial wave effect gradient field is that it can fully reflect the interactions among different sectors. As for study area, several concentrated mainly on central cities, provinces, inter-provinces, and even countries, but few studies considered urban agglomerations. At present, urban agglomerations have become a major spatial form in regional economic development, but their development still faces many problems, especially those in early stages, due to less flows of resources and technology among cities.

Therefore, in this study, we developed a framework to investigate the industrial spatial linkages in urban agglomeration by integrating the input-output theory and gravity model. First, based on the input-output theory, the wave effect gradient field was established to represent the interactions among different sectors. Then the inter-sectoral relations were evaluated by using response gradient and influence gradient. Second, this framework allows the evaluation of the industrial relation capacity of each sector and the total industry in each city. Third, we measured industrial spatial linkages between various cities by applying the gravity model, including the linkages for total industries and some major sectors. The urban agglomeration in the middle reaches of the Yangtze River (UAMRYR) was taken as the study area to examine this framework. Then, we discussed the optimization strategies of industrial development in the region. The results will provide a theoretical reference for the industrial layout planning of urban agglomeration, and a scientific basis for the promotion of economic linkages and cooperation among regions.

\section{Materials and Methods}

\subsection{Study Area}

The UAMRYR is located in central China, with latitudes $26^{\circ} 07^{\prime}-32^{\circ} 10^{\prime} \mathrm{N}$ and longitudes $110^{\circ} 15^{\prime}-118^{\circ} 29^{\prime}$ E, as shown in Figure 1. It covers a total area of approximately $317,000 \mathrm{~km}^{2}$, and occupies 3.3\% of China's total territory area. In 2016, the population and GDP of the UAMRYR were 121 million and 7.1 trillion RMB (about 1.1 trillion dollars), respectively, accounting for $8.8 \%$ and 9.6\% of the totals in mainland China. The UAMRYR consists of four subgroups: Wuhan Metropolitan Area (WMA), Ring of Changsha-Zhuzhou-Xiangtan Urban Agglomeration (RCZXUA), Poyang Lake Eco-economic Zone (PLEZ), and Xiang-Jing-Yi City Group (XJYCG). The three central cities, Wuhan, Changsha, and Nanchang, are distributed in a triangular configuration (see Figure 1b).

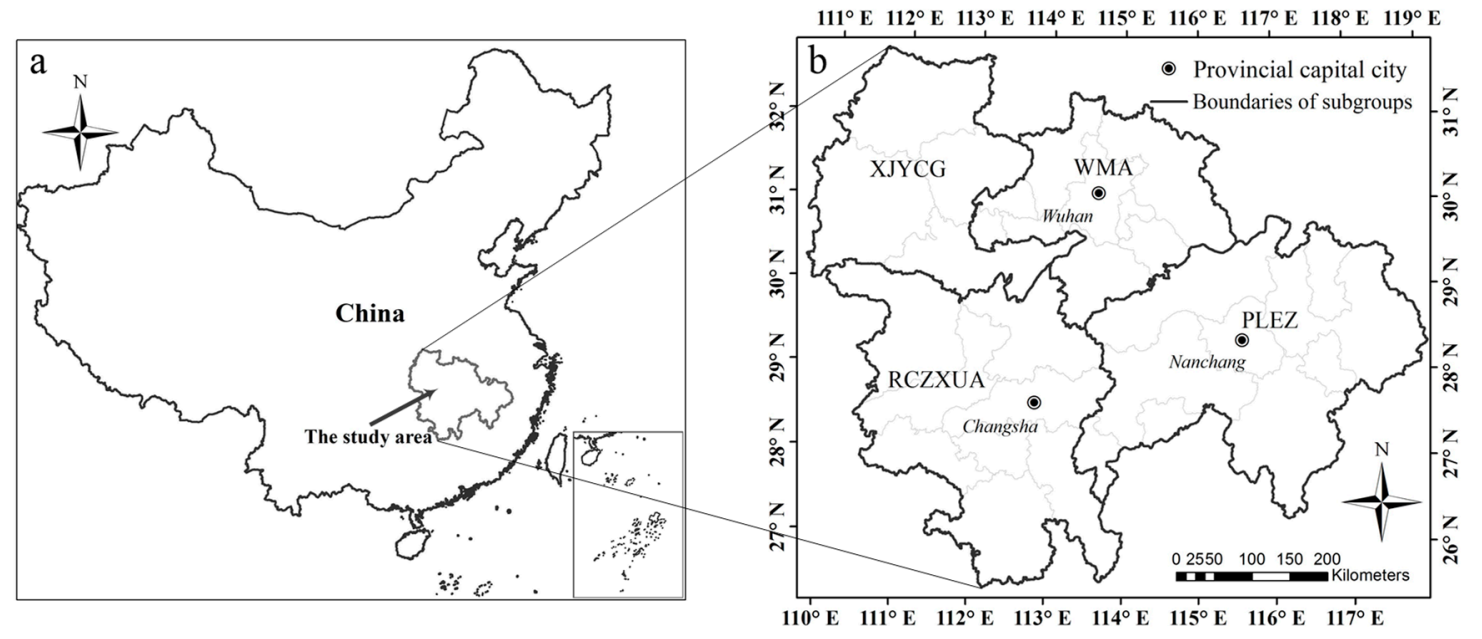

Figure 1. Location of study area: (a) location in China; and (b) urban agglomeration of the middle reaches of the Yangtze River (WMA: Wuhan Metropolitan Area; RCZXUA: Changsha-Zhuzhou-Xiangtan Urban Agglomeration; PLEZ: Poyang Lake Eco-economic Zone; XJYCG: Xiang-Jing-Yi City Group). 
After the release of the Development Plan of the Urban Agglomeration in the Middle Reaches of the Yangtze River in April 2015, all the provinces in central China have actively formulated a series of strategic cooperation agreements to strengthen the regional economic linkages in UAMRYR. However, there exist administrative barriers because of the short period since the UAMRYR was put forward. In recent years, industrial structures in Wuhan, Changsha, and Nanchang present similar characteristics, and UAMRYR still lacks for rational industrial division and cooperation. Therefore, it is very urgent to explore the industrial spatial linkages of UAMRYR, aiming at strengthening the regional economic linkages in UAMRYR and boosting the regional economic integration. In this article, UAMRYR, which is in its early stage of development, was chosen as the study area.

\subsection{Data Source}

Table 1 illustrates the classifications of industries. Referring to China's Classification of National Economic Industries (GB/T 4754-2011), the industry was further divided into 19 categories (excluding international organizations), and according to Chinese Input-Output Table (2012), the industry was divided into 42 subcategories. This study took the latest Chinese input-output table in 2012 as the input-output table of study area because China lacks input-output tables across provinces.

Table 1. Industry classification scheme.

\begin{tabular}{|c|c|}
\hline Categories & Sub Categories \\
\hline $\begin{array}{l}1 \text { Agriculture, forestry, animal husbandry } \\
\text { and fishery sector }\end{array}$ & (1) Agriculture, forestry, animal husbandry and fishery products and services \\
\hline 2 Extractive sector & $\begin{array}{l}\text { (2) Coal mining; } \\
\text { (3) Oil and gas extraction; } \\
\text { (4) Metal mining; } \\
\text { (5) Non-metallic minerals and other mining }\end{array}$ \\
\hline 3 Manufacturing sector & $\begin{array}{l}\text { (6) Food and tobacco; } \\
\text { (7) Textile; } \\
\text { (8) Textile clothing footwear leather down and its products; } \\
\text { (9) Woodworking and furniture; } \\
\text { (10) Paper printing and cultural and educational sporting goods; } \\
\text { (11) Oil, coking products and nuclear fuel processing; } \\
\text { (12) Chemical product; } \\
\text { (13) Non-metallic mineral products; } \\
\text { (14) Metal smelting and calendering products; } \\
\text { (15) Metal products; } \\
\text { (16) General Equipment; } \\
\text { (17) Professional setting; } \\
\text { (18) Transportation equipment; } \\
\text { (19) Electrical machinery and equipment; } \\
\text { (20) Communications equipment, computers and other electronic equipment; } \\
\text { (21) Instrumentation; } \\
\text { (22) Other manufacturing products; } \\
\text { (23) Waste scrap; } \\
\text { (24) Repair of metal products, machinery and equipment }\end{array}$ \\
\hline $\begin{array}{l}4 \text { Electricity gas and water production and } \\
\text { supply sector }\end{array}$ & $\begin{array}{l}\text { (25) Electricity and heat production and supply; } \\
\text { (26) Gas production and supply; } \\
\text { (27) Water production and supply }\end{array}$ \\
\hline 5 Building sector & (28) Building \\
\hline 6 Wholesale and retail trade sector & (29) Wholesale and retail \\
\hline $\begin{array}{l}7 \text { Traffic warehousing post and } \\
\text { telecommunications sector }\end{array}$ & (30) Transportation, warehousing and postal services \\
\hline 8 accommodation catering sector & (31) Accommodation and dining \\
\hline
\end{tabular}


Table 1. Cont.

\begin{tabular}{ll}
\hline \multicolumn{1}{c}{ Categories } & \multicolumn{1}{c}{ Sub Categories } \\
\hline $\begin{array}{l}\text { 9 Information transmission computer } \\
\text { services and software sector }\end{array}$ & (32) Information transmission, software and information technology services \\
\hline 10 Financial sector & (33) Financial \\
\hline 11 Real estate sector & (34) Real estate \\
\hline 12 Leasing and business services sector & (35) Leasing and business services \\
\hline $\begin{array}{l}13 \text { Scientific research and technical services } \\
\text { and geological prospecting sector }\end{array}$ & (36) Scientific research and technical services \\
\hline $\begin{array}{l}14 \text { Water conservancy, environment and } \\
\text { public facilities management sector }\end{array}$ & (37) Water, environment and public facilities management \\
\hline $\begin{array}{l}15 \text { Social organization and residents services } \\
\text { and other services sector }\end{array}$ & (38) Residents services, repairs and other services \\
\hline $\begin{array}{l}16 \text { Education sector } \\
\text { 17 Health, social insurance and social } \\
\text { welfare sector }\end{array}$ & (39) Education \\
\hline $\begin{array}{l}18 \text { Culture, sports and entertainment sector } \\
\text { 19 Public management and social }\end{array}$ & (41) Culture, sports and entertainment \\
\hline organization sector & (42) Public administration, social security and social organization \\
\hline
\end{tabular}

There are 31 cities in UAMRYR. Due to the lack of data in Xiantao, Tianmen, and Qianjiang, and the incompleteness of the Ji'an administrative region, we did not include these 4 cities in our analysis. The necessary data of the employed population of the remaining 27 cities were collected from the Chinese City Statistical Yearbook (2016). The spatial data were extracted from 1:4,000,000 national geographic information database (vector-based).

\subsection{Methodology}

The inter-sectoral interaction can be regarded as a form of potential energy of industrial relations within a city. As a result, the "field strength" of industrial linkages among cities will follow the distance-decayed law. The inter-sectoral interaction can be explained by input-output theory, and the distance-decayed law can be represented by using the gravity model. We designed a framework based on the input-output theory and the gravity model to examine the urban agglomerations' industry spatial linkages, as shown in Figure 2. First, the wave effect gradient field was calculated to represent the interactions among different sectors based on the input-output table. Second, the coefficients of response gradient and influence gradient were calculated to determine the inter-sectoral relations. On this basis, we evaluated the industrial relation capacity of each city, combined with the scale and industry relation capacity of each sector of each city. Third, the gravity model was applied to calculate the intensity of industrial spatial linkages for inter-city, including total industry and each sector. Finally, we identified the axes of industrial development after the spatial network of industrial clusters was created. 


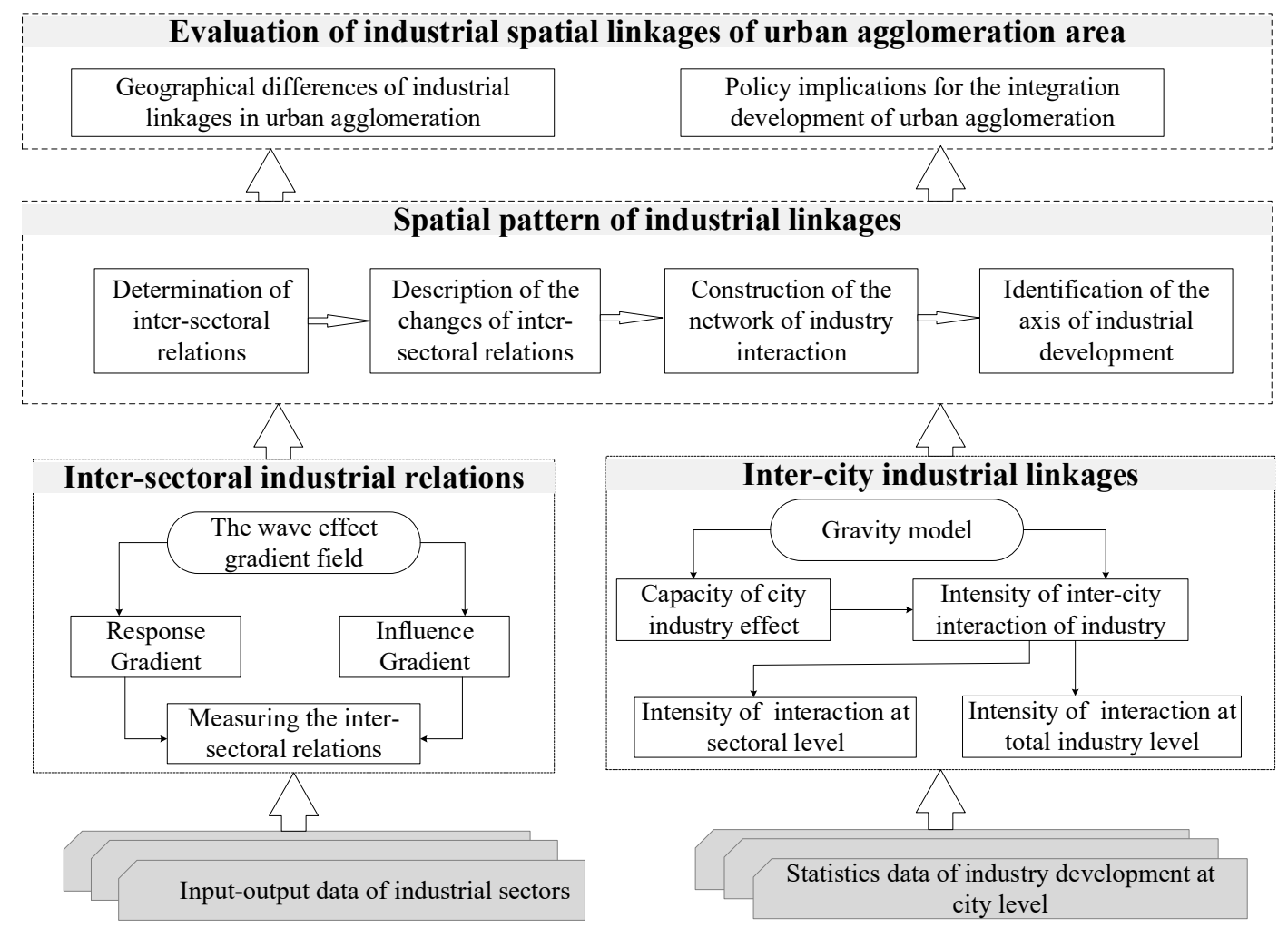

Figure 2. Conceptual framework.

\subsubsection{Calculation of Inter-Sectoral Relations Based on Input-Output Theory}

Input-output is a scientific analysis method to study the quantitative relationship among various sectors of the national economy and production. Input-output theory can give full consideration to the characteristics of different sectors, be conducive to better understanding the industrial spatial structure and development characteristics in urban agglomeration, and could provide more accurate information for the formulation of regional or national development plans.

\section{Wave Effect Gradient Field}

To better represent the concept of the "industrial field", the wave effect gradient field was calculated by the complete consumption coefficient matrix and direct consumption coefficient matrix in the input-output table, which achieved the transition from the industry inherent relation to the industrial spatial linkages. The wave effect of input-output is transmitted through the Leontief inverse matrix coefficients to various sectors, when the final demand changes. Here, it is assumed that the technical condition always remains unchanged and the inverse coefficient keeps stable. However, due to progress in technology, product structure, and industrial structure changes, the direct consumption coefficient will change very frequently. Hence, it will naturally cause a change in the direct consumption of related industries and total demand. These direct and wave changes, which are carried out in a network of different sectors, can be described by the wave effect field. Therefore, the wave effect gradient field can reflect the dynamic nature of the relationship among sectors and could be calculated by the following Equation (1) [32].

$$
\nabla \mathrm{B}=\sum_{k=2}^{n} \sum_{l=1}^{n}\left[\begin{array}{cccc}
b_{1 k} b_{l 1} & b_{1 k} b_{l 2} & \cdots & b_{1 k} b_{l n} \\
b_{2 k} b_{l 1} & b_{2 k} b_{l 2} & \cdots & b_{2 k} b_{l 2} \\
\vdots & \vdots & \ddots & \vdots \\
b_{n k} b_{l 1} & b_{n k} b_{l 2} & \cdots & b_{n k} b_{l n}
\end{array}\right] \bar{a}_{k l}
$$


where $\nabla \mathrm{B}$ is the wave effect gradient field, $b_{i j}$ is the element of the $i$-th row and the $j$-th column in the total demand coefficient matrix, $\bar{a}_{k l}$ is the unit vector corresponding to $a_{k l}$ in the $k$-th row and the $l$-th column of the direct consumption coefficient matrix, and $n$ indicates the number of industry sectors.

\section{Response Gradient and Influence Gradient of Each Sector}

Similar to the response coefficient and influence coefficient in the input-output model [18], we introduced response gradient and influence gradient to measure the degree of response and influence of an industry in the entire industrial space. The response gradient reflects the agglomeration effect of the economic development in urban agglomeration. A larger response gradient implied that this sector pushes more on other sectors. The influence gradient reflects the diffusion effect of urban economic development. A high influence gradient indicates that the sector has a larger pull effect on other sectors.

The response gradient depicts the response degree of demand that a sector receives, when one additional unit was added to each sector of the national economy system. In other words, the response gradient reflects the total amount of needs of this sector to provide for other sectors. The formula can be expressed as in Equation (2).

$$
S t_{i}=\frac{\frac{1}{n}\left|\sum_{j=1}^{n} \nabla b_{i j}\right|}{\frac{1}{n^{2}}\left|\sum_{i=1}^{n} \sum_{j=1}^{n} \nabla b_{i j}\right|},
$$

where $S t_{i}$ represents the response of the $i$-th industry sector affected by other sectors, and $\nabla b_{i j}$ is the coefficient of the $i$-th row and the $j$-th column in the wave effect gradient field. If $S t_{i}>1$, the response degree is higher than the average level of the entire economic system (the average response degree generated by each sector), which means the response of the $i$-th industry sector is a restriction. If $S t_{i}=1$, then the response degree is equal to the average level of the entire economic system, that is, the response of the $i$-th industry sector is neutral. If $S t_{i}<1$, then the response degree is less sensitive than the average level, which means the response of the $i$-th industry sector is a weak restriction.

Influence gradient refers to the extent to which a sector-generated production demand wave impacts on the other sectors of the economy system, when one unit of final use is added to this sector. The influence gradient can be calculated as:

$$
T t_{j}=\frac{\frac{1}{n}\left|\sum_{i=1}^{n} \nabla b_{i j}\right|}{\frac{1}{n^{2}}\left|\sum_{i=1}^{n} \sum_{j=1}^{n} \nabla b_{i j}\right|},
$$

where $T t_{j}$ represents the influence gradient value of the $j$-th industry impacting on other industry sectors. If $T t_{j}>1$, then the influence of industry sector $j$ is greater than the social average influence (the average wave effect that all sectors generated), which means the influence of the $j$-th industry sector is promoted. If $T t_{j}=1$, the influence of the $j$-th industry sector is equal to the social average influence-i.e., the influence of the $j$-th industry sector is neutral. If $T t_{j}<1$, then the influence of the $j$-th industry sector is lower than the social average influence, which implies that the influence of the $j$-th industry sector is slackened.

\section{The Inter-Sectoral Relations of Each Sector}

The linkage between an industrial sector and other industrial sectors reflects the impact of this sector on other sectors, and the influence by other sectors. If both of these are significant, it indicates that this sector has a close relationship with other sectors. Usually, the indicator of inter-sectoral relations can be explained by measuring the relevance of inter-sector technology. The inter-sectoral relation capacity of each sector can be defined as:

$$
C I_{m}=\beta_{m} \sum_{i=1}^{42}\left(\alpha_{i} S t_{i} T t_{i}\right)
$$


where $C I_{m}$ represents the inter-sectoral relation value of $m$ sector, $\alpha_{i}$ is the weight of different sub-categories of $i$ th-sector, and $\beta_{m}$ is the weight of categories of sector $m$. Considering the service radius, service threshold, internal technology association of industries, whether to meet the market demand, and other industrial development laws, the weight of the categories is calculated by using an analytic hierarchy process. When calculating the weight of different sub-categories, the response gradient and influence gradient should be considered.

\subsubsection{Intensity of Industrial Spatial Linkages for Inter-city (IISLI)}

\section{The IISLI of Total Industry}

In order to better represent the industrial spatial linkages between cities, an indicator to measure the industrial base of each city is required. Therefore, we put forward the concept of industrial relation capacity of city, where the indicator inter-sector relation is integrated. The intensity of industrial spatial linkage for inter-city with respect to total industry is denoted as:

$$
C I_{k}=\sum_{m=1}^{19} M c_{k-m} C I_{m}
$$

where $C I_{k}$ is the industry relation capacity of the $k$-th city, $M c_{m}$ is the employment population of $m$-sector, and $C I_{m}$ represents the value of the inter-sectoral relations of $m$-sector.

Differing from the industrial relation capacity, IISLI indicates the intensity of industrial spatial interaction. Due to the distance-decayed law of the industrial spatial interaction, the gravity model is used to calculate the IISLI of total industry. In this article, we take " 2 " as the distance decay coefficient, because it has been proved that the strength of an economic tie is inversely proportional to the square of the distance between two cities [9]. The formula can be expressed as Equation (6).

$$
C I_{k l}=K \frac{\sqrt{C I_{k} \cdot C I_{l}}}{D_{k l}^{2}}
$$

where $C I_{k l}$ is the IISLI of total industry between city $k$ and city $l, C I_{k}$ and $C I_{l}$ are the industrial relation capacities of the $k$-th city and the $l$-th city, respectively, $K$ is the gravitational constant (here $K=1$ ) [22], and $D_{k l}$ represents the Euclidean distance between city $k$ and city $l$ (based on city center).

\section{The IISLI of Each Sector}

Based on the calculation of intensity of industrial spatial linkages at the total industry level, we need to explore the spatial interaction at the industrial sector level, which will provide more detailed information on the spatial distribution and the interdependence relationship among different sectors in an urban agglomeration area. We defined the IISLI of each sector the same as the IISLI of total industry. The gravity model was used to calculate the indicator of spatial interaction intensity among cities of a sector, which is defined as:

$$
C I_{k l-m}=K \frac{\sqrt{\left(M c_{k-m} C I_{m}\right) \cdot\left(M c_{l-m} C I_{m}\right)}}{D_{k l}^{2}}
$$

where $C I_{k l-m}$ is the spatial interaction intensity of the $m$ th industry sector, $M c_{m}$ is the employment population of the $m$ th sector, $C I_{m}$ represents the inter-sectoral relation value of the $m$ th sector, and $K$ and $D_{k l}$ are the same as in Equation (6). 


\section{Results}

\subsection{Inter-Sectoral Relations Analysis}

\subsubsection{Response Gradient and Influence Gradient Measurement}

The wave effect gradient field was measured by employing the complete consumption coefficient and the direct consumption coefficient in Chinese Input-output Table (2012). Then, the response gradient and influence gradient were calculated according to Equations (1) and (2), as reported in Table 2.

Table 2. Response gradient and influence gradient based on Chinese Input-output Table (2012) [33].

\begin{tabular}{ccccccccc}
\hline Sector & RG & IG & Sector & RG & IG & Sector & RG & IG \\
\hline$(1)$ & 2.1444 & 0.4424 & $(15)$ & 0.9940 & 1.2874 & $(29)$ & 1.6338 & 0.2065 \\
$(2)$ & 1.2923 & 0.6762 & $(16)$ & 1.0682 & 1.3073 & $(30)$ & 1.8420 & 0.3680 \\
$(3)$ & 1.5350 & 0.7516 & $(17)$ & 0.5488 & 1.5289 & $(31)$ & 0.4807 & 0.8513 \\
$(4)$ & 0.9360 & 1.0322 & $(18)$ & 0.9439 & 1.5025 & $(32)$ & 0.3864 & 0.9786 \\
$(5)$ & 0.3987 & 1.0819 & $(19)$ & 1.1541 & 1.2646 & $(33)$ & 1.9387 & 0.1627 \\
$(6)$ & 1.5693 & 0.8623 & $(20$ & 2.0217 & 1.3280 & $(34)$ & 0.4085 & 0.3537 \\
$(7)$ & 1.5043 & 1.4595 & $(21)$ & 0.3614 & 1.7325 & $(35)$ & 1.1464 & 0.7914 \\
$(8)$ & 0.3572 & 1.6389 & $(22)$ & 0.0919 & 1.7440 & $(36)$ & 0.5670 & 1.1365 \\
$(9)$ & 0.6050 & 1.5278 & $(23)$ & 0.2905 & 0.4120 & $(37)$ & 0.1272 & 1.1572 \\
$(10)$ & 1.0018 & 1.1901 & $(24)$ & 0.0499 & 1.9228 & $(38)$ & 0.3218 & 0.8985 \\
$(11)$ & 1.6298 & 0.4739 & $(25)$ & 2.3841 & 0.4741 & $(39)$ & 0.0505 & 0.5026 \\
$(12)$ & 4.8058 & 0.0312 & $(26)$ & 0.1404 & 1.3061 & $(40)$ & 0.0164 & 1.3261 \\
$(13)$ & 0.8326 & 1.3632 & $(27)$ & 0.0761 & 1.1093 & $(41)$ & 0.1417 & 0.9395 \\
$(14)$ & 3.9246 & 0.5968 & $(28)$ & 0.2284 & 1.5535 & $(42)$ & 0.0490 & 0.7887 \\
\hline
\end{tabular}

Note: RG: Response gradient; IG: Influence gradient.

The results of response gradient showed that the manufacturing sector is most affected by other sectors, while public management, social security, and social organization are least affected by other sectors. The response gradient of various sectors is very different-from 4.8058 to 0.0164 (the former is 293 times greater than the latter). In addition, the 42 sectors can be divided into three classes, according to the value of the response gradient. The chemical products manufacturing sector and metal smelting and rolling processing sector have response value gradients, ranging from 3 to 5 . Most of manufacturing and a few service industries have response gradients in the range of 0.6-3. Almost all of the other 20 sectors with values from 0 to 0.6 are the tertiary industry.

The results of influence gradient indicated that manufacturing has greatly stimulated the development of other related industrial sectors. Compared with the value of response gradient, the range of influence gradient is much smaller. The 42 sectors of influence gradient value are in the range of $0.0312-1.9228$. These 42 sectors can be divided into three classes, according to the value of their influence gradient. Their sectors have value of influence gradients from 1.5 to 2 , and are generally metal-related manufacturing. There are 14 sectors with values ranging from $1-1.5$, most of which are manufacturing. There are 20 sectors with values in the range $0-1$, consisting of the tertiary industry and the primary industry. Among them, the chemical products manufacturing sector has the lowest influence gradient and the highest response gradient, indicating that it is much affected by other sectors and impact less on other sectors.

\subsubsection{Inter-Sectoral Relations Measurement}

Evaluating the degree of association among different sectors is of great importance, to reflect their development level and overall technical level. The inter-sectoral relation values of all sectors were calculated with Equation (4) and sorted in descending order. As revealed in Table 3, the information transmission, computer services, software sector, scientific research and technical services and geological prospecting sector, manufacturing sector, and financial sector, are in the top four 
positions, which means these four sectors are at the higher level of the industry system. Meanwhile, the agriculture, forestry, animal husbandry and fishery sector, extractive sector, accommodation catering sector, public management and social organization, resident services, and other services sector, are the last four, indicating that they are at the bottom of the industry system. In the premise of ensuring life and production, the high level of sectors should be given a priority to triggering regional economic development. In recent years, China has already been transformed into a service-oriented industry. However, the manufacturing sector should still be developed vigorously to meet the demand for various products and to provide employment opportunities. For mitigating the ecological and environmental problems caused by economic development, policymakers should accelerate the adjustment of the industrial structure and encourage high-tech industry sectors, and realize a rapid transformation from the traditional manufacturing sector to an advanced manufacturing sector. All industries shifted from independent operations to correlation, enabling most sectors to maintain linkages with other sectors through the industrial chain.

Table 3. Inter-sectoral relations of each sector in 2012.

\begin{tabular}{ccccccccc}
\hline Number & Sector & IR & Number & Sector & IR & Number & Sector & IR \\
\hline$(1)$ & 9 & 0.3851 & $(8)$ & 14 & 0.0280 & $(15)$ & 1 & 0.0146 \\
$(2)$ & 13 & 0.2732 & $(9)$ & 18 & 0.0265 & $(16)$ & 2 & 0.0146 \\
$(3)$ & 3 & 0.2705 & $(10)$ & 12 & 0.0241 & $(17)$ & 8 & 0.0102 \\
$(4)$ & 10 & 0.1642 & $(11)$ & 5 & 0.0232 & $(18)$ & 19 & 0.0067 \\
$(5)$ & 11 & 0.0875 & $(12)$ & 6 & 0.0159 & $(19)$ & 15 & 0.0064 \\
$(6)$ & 17 & 0.0456 & $(13)$ & 16 & 0.0159 & & & \\
$(7)$ & 4 & 0.0312 & $(14)$ & 7 & 0.0147 & & & \\
\hline
\end{tabular}

Note: IR: Inter-sectoral relation.

\subsection{Analysis of the Industrial Spatial Linkages in Urban Agglomeration Area}

\subsubsection{Analysis of the Features of Industrial Spatial Linkages}

With Equation (6), we obtained the IISLI of the total industry in 2015, and there are a total of 351 linkages. The values of IISLI were multiplied by $10^{5}$ in order to amplify the differences of industrial spatial linkages. For the purpose of visualization, we only plotted the linkages whose values are in the first half, illustrated in Figure 3. We divided these linkages into six classes, according their values, which can better illustrate the different levels of IISLI at the total industry level.

\section{Differences of Industrial Spatial Linkages}

As described in Figure 3a, the IISLI value of total industry in UAMRYR is remarkably different. Wuhan-Xiaogan's is the strongest (127.4882), while Loudi-Yingtan's is the lowest (0.1497). The former is 851 times greater than the latter.

From the perspective of the intensity of industrial spatial linkages, WMA, RCZXUA, PLEZ, and XJYCG have formed self-organized systems, and the pattern of linkage intensity presents great difference (Figure 3). It indicated that the regional development in UAMRYR did not break through the restrictions of administrative boundaries in the early period. The average IISLI of WMA was 10.5169, which indicates the strongest interaction among industry sectors. RCZXUA was the second largest, with a value of 8.8311, followed by XJYCG (8.4397). PLEZ had the lowest value, of 5.7742. The spatial linkages of UAMRYR as a whole showed a gradual decrease from east to west, where the industrial spatial linkages between WMA and RCZXUA still need to be strengthened.

In terms of spatial features of IISLI, each subgroup has presented a different spatial structure (Figure 3b). WMA shows obvious "centrifugal radiation" characteristics, with the rays of "Wuhan-Xiaogan, Wuhan-Ezhou, Wuhan-Huanggang, Wuhan-Huangshi, and Wuhan-Huangshi" (Figure 3a). This indicates that WMA had very strong industrial linkages from Wuhan to the 
periphery cities. It had even radiated from the "Wuhan-Ezhou-Huangshi-Jiujiang-Nanchang" to PLEZ. PLEZ formed a radiation structure with axis of "Nanchang-Jiujiang, Nanchang-Yichun, Yichun-Xinyu, Nanchang-Shangrao, and Nanchang-Fuzhou". The overall regional linkage intensity was weak. Nanchang did not assume the role of a core city. The industrial linkages of RCZXUA presented an elementary network structure, with the links of "Changsha-Yueyang, Changsha-Yiyang, Yiyang-Changde, Changsha-Xiangtan, Xiangtan-Hengyang, Hengyang-Zhuzhou, Zhuzhou-Pingxiang, Pingxiang-Changsha, and Changsha-Zhuzhou". The industrial linkage of XJYCG was described as "Xiangyang-Yichang, Yichang-Jingzhou, Jingzhou-Jingmen, Jingmen-Xiangyang, and Jingmen-Yichang", with the pattern of a relatively balanced network. Compared with the other three subgroups, the industrial linkages of XJYCG were weaker, where effective measures should be taken to strengthen links with WMA and RCZXUA.

As for the subgroup bordering areas, Jiujiang is a connection node in the WMA and PLEZ, where an industrial belt of "Wuhan-Huangshi-Jiujiang-Nanchang" forms. In contrast, Yueyang and Xianning, as the key city in the bordering area of WMA and RCZXUA, have not been frequently communicating with other cities.
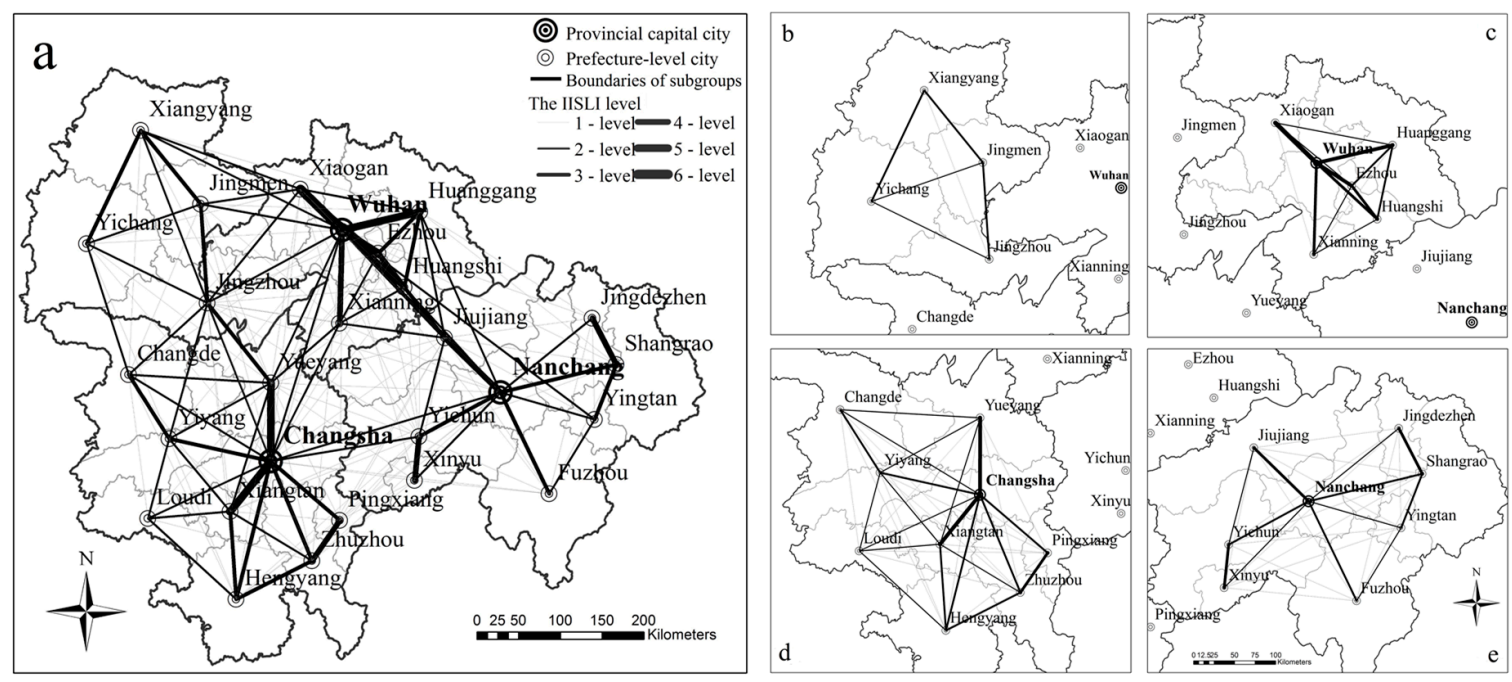

Figure 3. Network of IISLI of the total industry (IISLI: Intensity of Industrial Spatial Linkages for Inter-city): (a) The study area; (b) XJYCG: Xiang-Jing-Yi City Group; (c) WMA: Wuhan Metropolitan Area; (d) RCZXUA: Changsha-Zhuzhou-Xiangtan Urban Agglomeration; (e) PLEZ: Poyang Lake Eco-economic Zone.

\section{Industrial Development Planning}

To determine the direction of industrial development and clarify the key points of industrial development, we explored the industrial development axis according to the IISLI of UAMRYR. We calculated and visualized the sum of the industrial linkages between each city and other cities, as shown in Figure 4. The figure shows that UAMRYR has formed two major industrial development axes. Axis 1 develops along the direction of "Xiaogan-Wuhan-Ezhou-Huangshi-Jiujiang-Nanchang", while axis 2 was along with "Yueyang-Changsha-Xiangtan". It can be seen that the industrial development between axes 1 and 2 is relatively independent and has not yet formed a closed linkage. This demonstrates that WMA and PLEZ have developed a close relationship, while RCZXUA does not closely interact with WMA and PLEZ. Among them, the industrial spatial linkages of Wuhan were apparently higher than other cities, which is in the leading position of the industry layout. Xiaogan and Changsha also showed strong industrial spatial linkages. In fact, this is inevitably dependent on their good industrial foundation and the advantage of their location. From this point of view, Nanchang's industrial spatial linkages are a little weaker, indicating that its industrial division and cooperation 
with surrounding cities are insufficient. In the process of development, UAMRYR should focus on the main axis of industrial linkages and guide and control the intensity and direction of industrial linkages, so as to improve the efficiency of industrial space utilization and advance the sustainable development of industrial space in UAMRYR. First, priority should be given to the development of the area between axes 1 and 2 to improve the industrial linkages among the subgroups. Meanwhile, the economic linkages along the "Jingguang" high-speed railway and the "Shanghai-Kunming" high-speed railway should be strengthened, so as to cultivate and develop an industrial development network among RCZXUA, WMA, and PLEZ. Second, the cities of the central area should enhance their radiation effect on the peripheral areas, and the cities in west Hubei, the western region of Hunan and southern Jiangxi, should gradually achieve industrial integration with their central cities.

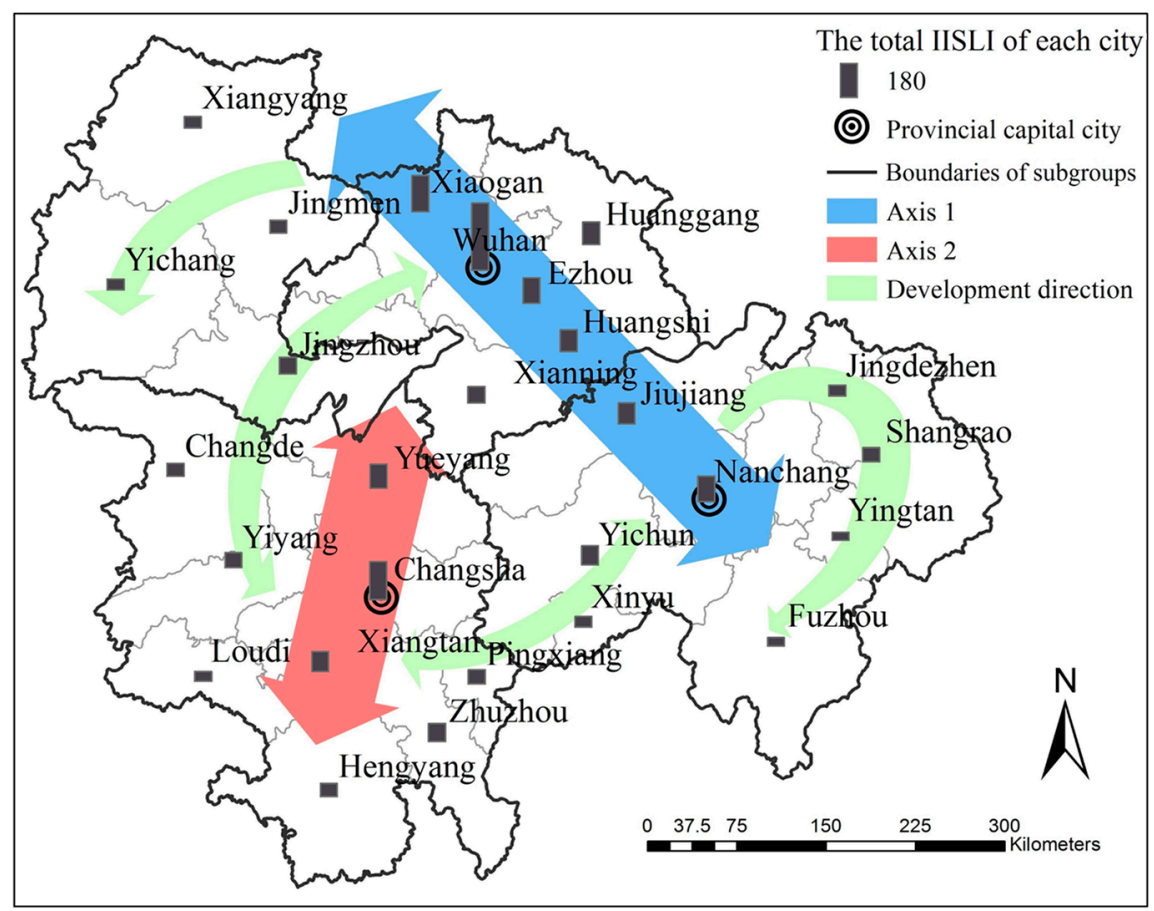

Figure 4. Map of industrial linkage axes.

\subsubsection{Spatial Linkage Characteristics of Each Sector}

In this study, we selected four sectors with the strongest industrial linkages (as in Table 2) to reveal the characteristics of industrial spatial linkages after the IISLI of 19 sectors was obtained with Equation (7). These industrial linkages were visualized by ArcGIS (see Figure 5). As Figure 5 shows, the IISLI of each sector exhibits different characteristics.

As shown in Figure 5a, the IISLI of the information transmission, software, and information technology services sector have similar patterns to the total industry. The strongest one of the information sector is "Wuhan-Xiaogan", with a value of 17.6117. The weakest one was "Loudi-Yingtan", with 0.0198 . The average linkage intensity was 0.5163. At present, it has formed the linkage spindle, which is "Xiaogan-Wuhan-Ezhou-Huangshi-Jiujiang-Nanchang" between WMA and PLEZ. WMA and RCZXUA also initially formed a "Wuhan-Xianning-Yueyang-Changsha-Xiangtan" information sector axis. Obviously, the linkages of information sector of RCZXUA and PLEZ have not yet formed a linkage axis. WMA, RCZXUA, and PLEZ were self-contained with the structure of radiation shape, while the correlation among cities of XJYCG was loose. Xianning, located at the boundary of the Hubei province with a close tie to Wuhan, has formed a network structure with three subgroups. Nevertheless, its linkages with Jiujiang and Yueyang should be enhanced so that more close information sector linkages will be achieved in the hinterland of UAMRYR. 
The IISLIs of the scientific research, technical services, and geological prospecting sectors were relatively balanced, compared with other sectors. The strongest linkage of the science and technology sector is "Wuhan-Xiaogan", with a value of 19.2595. The weakest one was "Loudi-Shangrao", with 0.0108. The average linkage intensity was 0.5099 . The spatial linkages of WMA were remarkably strong, and the scientific and technological sector of Wuhan had an apparent radiation effect to its periphery cities. RCZXUA expanded to the surrounding cities along the axis of "Yueyang-Changsha-Xiangtan". Although XJYCG already had preliminary spatial linkages within the region, the external linkages with WMA and RCZXUA should be strengthened. Meanwhile, the linkages between PLEZ and RCZXUA were insufficient. PLEZ has formed a radiation line of "Xiaogan-Wuhan-Huangshi-Jiujiang-Nanchang" linked with WMA, but the external industrial radiation of Nanchang was relatively weak.
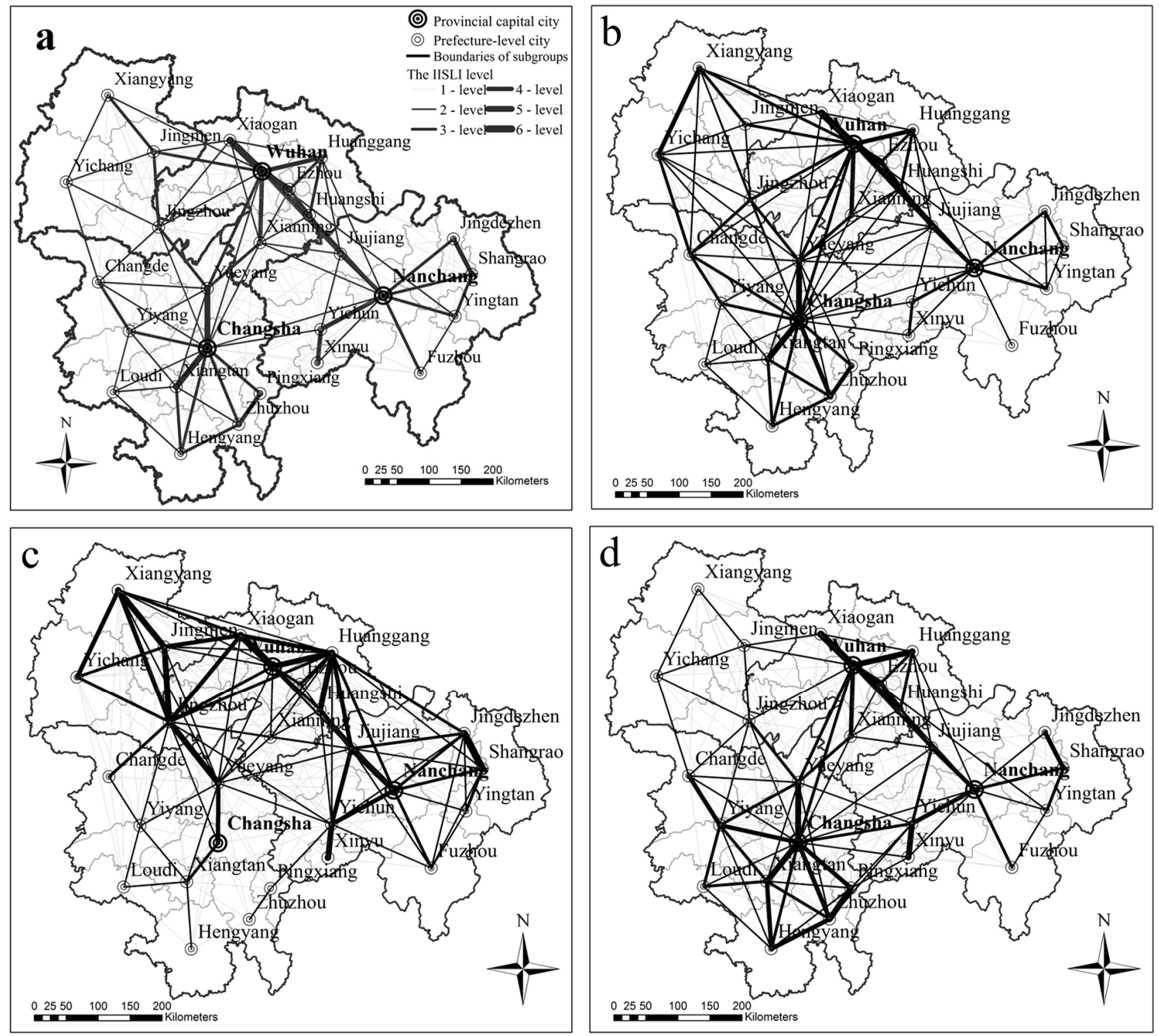

Figure 5. Linkages network of various sectors (IISLI: Intensity of Industrial Spatial Linkages for Inter-city): (a) Information transmission, software and information technology services sector; (b) scientific research, technical services and geological prospecting sector; (c) manufacturing sector; (d) financial sector.

The IISLI of manufacturing sector was illustrated in Figure 5c. "Wuhan-Xiaogan" has the strongest linkage in the manufacturing sector, with the value of 4.4262. The weakest one was "Ezhou-Hengyang", with 0.0032 . The average linkage intensity is 0.1924 . There are two main spindles of the manufacturing interaction among different cities "Xiangyang-Jingmen-Jingzhou-Yueyang-Changsha-Xiangtan" and "Yichang-Xiangyang-Jingmen-Xiaogan-Wuhan-Ezhou-Huangshi-Jiujiang-Nanchang". In addition, Huanggang has formed a remarkable "fan-shaped" structure with its surrounding cities. WMA, 
XJYCG, and PLEZ, the three subgroups, have formed an obvious linkage, while RCZXUA was excluded. The manufacturing of other cities around Xianning had more close linkages, but Xianning did not. This is because Xianning had no advantage in population and economic aggregate. In contrast, Yueyang and Jiujiang have already established strong manufacturing linkages with other cities.

The IISLI of the financial sector was visualized in Figure $5 \mathrm{~d}$. The strongest linkage of the financial sector is "Wuhan-Xiaogan", with a value of 14.1583. The weakest one is "Loudi-Jingdezhen", with 0.0204. The average linkage intensity was 0.5499 . Compared with the other sectors, the industrial division and cooperation of the financial sector was greater, and the development is at a relatively high level. In WMA, Wuhan had remarkable radiation effect on its surrounding cities in the financial sector, especially the linkages of "Wuhan-Xiaogan, Wuhan-Huanggang, Wuhan-Xianning, Wuhan-Ezhou, Wuhan-Huangshi, and Ezhou-Huangshi". In RCZXUA, the linkage network pattern was highlighted by "Yueyang-Changsha-Yiyang and Changsha-Xiangtan-Hengyang-ZhuzhouPingxiang-Changsha-Zhuzhou". In PLEZ, the radiation pattern can be found with the radiation center of Nanchang. Unfortunately, XJYCG had close correlations with neither the internal cities nor the external subgroups.

In general, the spatial linkages of various sectors have different characteristics. The spatial interaction characteristics of the information transmission, computer services, and software sectors and the scientific research, technical services, and geological prospecting sectors are similar to those of the total industry, which indicates that the high-tech and internet industry contribute most to economic ties among cities. From the view of the intensity of industrial spatial linkages, WMA was the most balanced and well-developed. With respect to single linkage, "Wuhan-Xiaogan" has the strongest spatial linkage in all four sectors, which corresponds to the actual development patterns in the region. Obviously, Xiaogan is closest to Wuhan (the central city of WMA). It has good economic development and a prominent location advantage. Recently, due to industrial transfer from Wuhan, Xiaogan has built a large number of industrial parks, such as Huagong Technology Xiaogan Electronic Industrial Park, Wuhan Optical Valley Xiaogan Industrial Park, Wuhan Auto Parts Xiaogan Industrial Park, Tongji Science and Technology Park, and Hanzheng Street Business Industrial Park. The economic integration and urbanization between Wuhan and Xiaogan have been accelerated remarkably. In addition, except for the financial sector, the other three sectors of Xianning, Yueyang, and Jiujiang have begun to cooperate, which demonstrates that the central area of UAMRYR will become more important for links among the four subgroups. As for the industrial development of each subgroup, the development of the financial sector in XJYCG lagged behind, and we find that the linkages of the manufacturing sector in RCZXUA and the linkages of the research, technical services, and geological prospecting sectors in PLEZ are the weakest.

\section{Discussions}

\subsection{Analyzing Industrical Spatial Linkage Needs a Multi-Level Framework}

The industrial spatial linkages of urban agglomeration determine the economic development level of urban agglomeration, to some extent. Recognizing the spatial structure and direction of economic development and allocating resources rationally are very important for sustainable economy development. Therefore, it is necessary for us to quantify the spatial linkages of urban agglomeration so as to provide reference for development planning. Although there are some studies on industrial spatial linkages, their focuses are different. Existing studies mainly focused on the spatial configuration of a certain link in the industrial chain or a single industrial sector. Most of these studies only provide partial references for regional economic development planning and policy making. This article took into account the multi-level spatial linkages that can reflect the contribution of different sectors to the inter-city linkages, thus providing a more comprehensive policy reference. In terms of research methods, there are only a few existing methods considering the interactions between industry sectors. In fact, the interaction of different sectors in an industrial chain always exists. Ignorance of this 
interaction will lead to deviations when we measure the industrial spatial linkages. Nevertheless, input-output theory and the wave effect gradient field used in this study can consider in more detail the interactions between different industrial sectors. As for research area, most existing studies concentrate on cities, provinces, inter-provinces, and even nations, and there are not many studies conducted on the industrial spatial linkages within the context of urban agglomeration areas. Therefore, it is necessary to establish a framework to study the industrial spatial linkages of urban agglomeration areas based on the input-output theory. Compared with the urban flow model and social network analysis, the input-output theory can remedy the lack of consideration of input-output effects in previous regional economic linkage studies. We can not only systematically analyze the external industrial spatial linkages of total industry of individual cities, but also explore the internal spatial linkages of individual industrial sectors. This study enriches the quantitative analysis on the spatial interaction of individual industry sectors, which will provide a new perspective for the study of spatial structure of urban agglomeration.

\subsection{Combining the Input-Output Theroy and Gravity Model Is Feasible}

The input-output theory and the gravity model were integrated into the proposed framework. First, we considered the interaction between different industry sectors based on input-output theory, when studying the industrial spatial linkages of urban agglomeration. Input-output tables are easily accessible, while input-output analysis is a feasible approach, as suggested in the field of economics. Second, the concept of gradient in mathematics is introduced into the wave effect gradient field, which can fully demonstrate the interaction between different industry sectors. The wave effect gradient field can be calculated by employing the matrix function of gradient in mathematics. Finally, we applied the gravity model as a measure of inter-city industrial spatial linkages. The gravity model has been demonstrated to be effective and reliable in many studies of industrial spatial linkages in urban agglomeration $[9,12]$. The above suggests that the framework is theoretically feasible.

We had applied the proposed framework to investigate the industrial spatial linkages in UAMRYR. We evaluated the inter-sectoral relations based on Input-output Table in 2012. The results of intensity of industrial linkages were slightly different from those of Fang et al. [3], but the relative order is generally the same. The result of this article shows that UAMRYR has an insufficient industrial spatial linkage, and each subgroup of UAMRYR forms its self-contained industrial cluster. This is consistent with the majority of other studies in the UAMRYR area. For example, Zhou et al. had studied its spatial linkage based on the urban flow model and the gravity model. The results show that the manufacturing and construction sectors have relatively strong radiation capabilities, while the central cities have slightly radial influence to their peripheral cities, where the intensity of industrial spatial linkages are uneven in UAMRYR [34]. Li et al. examined the spatial economic linkages and structural patterns in UAMRYR by using a modified gravity model. The results indicated that each subgroup is relatively independent [35]. Thus, our practical application has demonstrated the feasibility and applicability of the integrated framework.

\subsection{Limitations and Future Research Directions}

Although the framework we proposed in this article can better demonstrate the industrial spatial linkages and development characteristics of urban agglomerations, limitations still exist. As for research methods, in this study we only used unidirectional values to represent the industrial inter-city linkages. However, the mutual inter-city attraction is often unequal. In future studies, we will modify the gravity model to adjust the interaction strength. Furthermore, this article did not explore the causes of IISLI. In the future, we can study the influential factors of industrial spatial linkages and clarify how to enhance the industrial spatial linkages between cities. 


\section{Conclusions}

Industrial spatial linkage, established by various sectors of the national economy in the process of social production, is a relationship of the direct or indirect mutual influence and constraint. In this relation, the development of a certain industry will have different impacts on other associated sectors, thus affecting the operation of the entire national economy system. Studying the industrial spatial linkages at the urban agglomeration scale can help understand the spatial structure and industrial relationship of urban agglomeration, and provide a valuable reference for planning and policy making in a timely manner. Adopting reasonable and effective policies to adjust the industrial structure and layout will help the regional economy achieve sustainable development. In this article, we proposed a framework to study the industrial spatial linkages of urban agglomeration. The wave effect gradient field approach and gravity model were integrated into the framework. The wave effect gradient field was used to analyze the inter-sectoral relation at the sector level, while the gravity model was adopted to explore the spatial relationship of total industry at the inter-city level. The integrated analysis framework can be used to depict the relationship between different regional economic systems at a more detailed level.

The urban agglomeration in the middle reaches of the Yangtze River has been taken as the study area, which is in the initial stage of regional development. It is crucial to reveal the situation of industrial spatial linkages and discover the bottleneck for regional planning and policy making. Based on the proposed method, the industrial spatial linkages have been analyzed. The results showed that the manufacturing sector is obviously in the dominant position and has the strongest influence on other sectors. The information transmission, computer services, and software sectors, scientific research, technical services, and geological exploration sectors, manufacturing sector, and financial sector have stronger linkages with other sectors. These four sectors could greatly affect national economic development. Their prosperity and stability are crucial to trigger macro-economy sustainable development. Policymakers should therefore pay more attention to promoting the development of these sectors. At the inter-city level, industrial spatial linkages demonstrate that the overall industrial linkages of UAMRYR are insufficient. WMA, RCZXUA, and PLEZ have been aggregated respectively. The industrial division and cooperation in WMA are much better than those of other subgroups, while PLEZ and XJYCG have a relatively weak industrial linkage. In the hinterland of UAMRYR, although Xianning, Yueyang, and Jiujiang have a key locational advantage, the intensity of industrial spatial linkages in these three cities is obviously insufficient. Wuhan has formed significant radiation linkages with its peripheral cities. Changsha and Nanchang also have better industries backgrounds. However, the industrial spatial linkages between the central cities still need to be strengthened. It is our suggestion that UAMRYR should further break the restrictions of administrative boundaries and gradually establish close ties at the inter-city level in future development. First of all, it should intensify cooperation at the administrative border areas, such as Yueyang, Xianning, and Jiujiang. Then, the industrial linkages between subgroups should be strengthened gradually, especially the linkage between RCZXUA and PLEZ. It is necessary to further improve the industrial division and enhance the industrial relation capacity in urban agglomeration. In addition, we should take full consideration of each city's characteristics to adjust the industrial structure and layout moderately, in order to achieve sustainable development.

This framework provides support for investigations on the industrial spatial linkages in urban agglomeration. The case study had demonstrated the usability of the framework, which not only enriched the methodology for the study of industrial spatial linkages, but also provided a new perspective for investigations on the spatial structure of urban agglomeration. This framework can be applied to provincial, inter-provincial, and national areas, or any other urban agglomeration area.

Author Contributions: Y.Yu and Q.H. participated in all phases and contributed equally to this work, including the establishment and application of the framework as well as the paper writing. W.T. revised the whole paper. Y.Yuan advised in the process of paper writing. Y.T. performed part of the experimental data collection. All authors contributed to the experiment design, and have read and approved the final manuscript. 
Acknowledgments: This work was supported by the National Natural Science Foundation of China (No. 41471339, 41571514) and the Fundamental Research Funds for the Central Universities of China (No. 185208017).

Conflicts of Interest: The authors declare no conflict of interest.

\section{References}

1. Wang, Z.; Deng, Y.; Song, X.K.; Wu, B. The complexity analysis of the spatial structure in Shanghai. Prog. Geogr. 2001, 20, 334-340. [CrossRef]

2. Yu, Y.; Tong, Y.; Tang, W.W.; Yuan, Y.B.; Chen, Y. Identifying Spatiotemporal Interactions between Urbanization and Eco-Environment in the Urban Agglomeration in the Middle Reaches of the Yangtze River, China. Sustainability 2018, 10, 290. [CrossRef]

3. Fang, C.L.; Song, J.T.; Lin, X.Q. The Theory and Practice of Sustainable Development of Urban Agglomeration in China, 1st ed.; Science Press: Beijing, China, 2010; pp. 161-199. ISBN 978-7-03-027192-1. (In Chinese)

4. O'Kelly, M.; Bryan, D. Agricultural location theory: Von Thünen's contribution to economic geography. Prog. Hum. Geogr. 1996, 20, 457-475. [CrossRef]

5. Perroux, F. Economic space: Theory and applications. Q. J. Econ. 1950, 64, 89-104. [CrossRef]

6. Friedmann, J. The Spatial Organization of Power in the Development of Urban Systems. Dev. Chang. 1972, 4, 12-50. [CrossRef]

7. Pred, A.R. Diffusion, organizational Spatial Structure, and City-System Development. Econ. Geogr. 1975, 51, 252-268. [CrossRef]

8. Zipf, G.K. The Unity of Nature, Least-Action, and Natural Social Science. Sociometry 1942, 5, 48-62. [CrossRef]

9. Sun, Q.; Tang, F.H.; Tang, Y. An economic tie network-structure analysis of urban agglomeration in the middle reaches of Yangtze River based on SNA. J. Geogr. Sci. 2015, 25, 739-755. [CrossRef]

10. Tan, R.H.; Zhou, K.H.; He, Q.S.; Xu, H.Z. Analyzing the Effects of Spatial Interaction among City Clusters on Urban Growth-Case of Wuhan Urban Agglomeration. Sustainability 2016, 8, 759. [CrossRef]

11. Djankov, S.; Freund, C. Trade Flows in the Former Soviet Union, 1987 to 1996. J. Comp. Econ. 2002, 30, 76-90. [CrossRef]

12. Lee, J.; Hoshino, S. GIS-Based Evaluation of Spatial Interactions by Geographic Disproportionality of Industrial Diversity. ISPRS Int. J. Geo-Inf. 2017, 6, 352. [CrossRef]

13. Zheng, Q.J.; Dai, T.Q.; Tao, Z.L.; Zhang, M.M. Spatial heterogeneity of gravity model parameters: A case study of inter-city railway passenger flow in China. Prog. Geogr. 2014, 33, 1659-1665. [CrossRef]

14. Li, S.; Wang, Z.; Zhong, Z.Q. Gravity Model for Tourism Spatial Interaction: Basic Form, Parameter Estimation, and Applications. Acta Geogr. Sin. 2012, 76, 526-544. [CrossRef]

15. Li, Z.L.; Sun, L.; Geng, Y.; Dong, H.; Ren, J.; Liu, Z.; Tian, X.; Yabar, H.; Higano, Y. Examining industrial structure changes and corresponding carbon emission reduction effect by combining input-output analysis and social network analysis: A comparison study of China and Japan. J. Clean. Prod. 2017, 162, 61-70. [CrossRef]

16. Wang, M.; Kuang, Y.Q.; Huang, N.S. Sustainable Urban External Service Function Development for Building the International Megalopolis in the Pearl River Delta, China. Sustainability 2015, 7, 13029-13054. [CrossRef]

17. Sun, X.D.; Li, J.S.; Qiao, H.; Zhang, B. Energy implications of China's regional development: New insights from multi-regional input-output analysis. Appl. Energy 2017, 196, 118-131. [CrossRef]

18. Shi, Q.L.; Deng, X.Z.; Shi, C.C.; Chen, S.Y. Exploration of the intersectoral Relations Based on Input- Output Tables in the River Basin of China. Sustainability 2015, 7, 4323-4340. [CrossRef]

19. Sun, D.Q.; Zhang, J.X.; Hu, Y.; Zhou, L.; Yu, Z.S. The Formation of Metropolitan Shadow from the Perspective of Industry Spatial Contacts: A Comparison Between Changjiang River Delta and Beijing-Tianjin-Hebei Metropolitan Region. Sci. Geogr. Sin. 2013, 9, 1043-1050. [CrossRef]

20. Cao, W.D.; Li, Y.Y.; Cheng, J.Q. Location patterns of urban industry in Shanghai and implications for sustainability. J. Geogr. Sci. 2017, 27, 857-878. [CrossRef]

21. Zhu, D.C.; Sun, J.M.; Lu, L. Spatial-temporal Evolution of Hefei Economic Circle's Spatial Correlation. Sci. Geogr. Sin. 2017, 37, 738-747. [CrossRef]

22. Wang, Z.B.; Xu, G.; Bao, C.; Xu, J.B.; Sun, F.H. Spatial and economic effects of the Bohai Strait Cross-Sea Channel on the transportation accessibility in China. Appl. Geogr. 2017, 83, 86-99. [CrossRef]

23. Matsumoto, H. International Urban Systems and Air Passenger and Cargo Flows: Some Calculation. J. Air Transp. Manag. 2004, 10, 241-249. [CrossRef] 
24. Thonhofer, E.; Palau, T.; Kuhn, A.; Jakubek, S.; Kozek, M.E. Macroscopic traffic model for large scale urban traffic network design. Simul. Model. Pract. Theory 2018, 80, 32-49. [CrossRef]

25. Ke, W.Q.; Chen, W.; Yu, Z.Y. Uncovering Spatial Structures of Regional City Networks from Expressway Traffic Flow Data: A Case Study from Jiangsu Province, China. Sustainability 2017, 9, 1541. [CrossRef]

26. Xu, Q.; Mao, B.H.; Bai, Y. Network structure of subway passenger flows. J. Stat. Mech. Theory. E 2016, 2016, 033404. [CrossRef]

27. Tobiassen, A.E.; Pettersen, I.B. Exploring open innovation collaboration between SMEs and larger customers The case of high-technology firms. Balt. J. Manag. 2018, 13, 65-83. [CrossRef]

28. Chand, S.; Aouad, G.; Dixit, V.V. Long-Range Dependence of Traffic Flow and Speed of a Motorway Dynamics and Correlation with Historical Incidents. Transp. Res. Rec. 2017, 2616, 49-57. [CrossRef]

29. Wu, Q.B.; Yue, Y.M. China's urban network based on spatial organization of electronic information enterprises. Geogr. Res. 2012, 31, 207-219. (In Chinese)

30. Wen, T.H.; Chin, W.C.; Lai, P.C. Understanding the topological characteristics and flow complexity of urban traffic congestion. Physica A. 2017, 473, 166-177. [CrossRef]

31. He, J.H.; Li, C.; Yu, Y.; Liu, Y.L.; Huang, J.L. Measuring urban spatial interaction in Wuhan Urban Agglomeration, Central China: A spatially explicit approach. Sustain. Cities Soc. 2017, 32, 569-583. [CrossRef]

32. Yang, X.W. A Grads Field Mold on Analysis of Industrial Relations. Sci. Technol. Prog. Policy 2005, 6, 86-88. [CrossRef]

33. Chinese Input-Output Association. Chinese Input-output Table in 2012. Available online: http:/ /www.stats. gov.cn/ztjc/tjzdgg/trccxh/zlxz/trccb/201701/t20170113_1453448.html (accessed on 1 June 2017).

34. Zhou, X.Y.; Hua, M.; Qin, Y.W.; Ma, X.X. Urban agglomeration spatial relationship research in the middle reaches of Yangtze River. Resour. Environ. Yangtze Basin 2016, 25, 1492-1500. [CrossRef]

35. Li, L.; Cai, L.J. The Characteristics of the Spatiotemporal Evolvement of Urban Economic Links in the Central Triangle City Cluster. Urban Probl. 2015, 61-70. [CrossRef]

(C) 2018 by the authors. Licensee MDPI, Basel, Switzerland. This article is an open access article distributed under the terms and conditions of the Creative Commons Attribution (CC BY) license (http:// creativecommons.org/licenses/by/4.0/). 